\title{
Faceted single crystals of mesoporous silica SBA-16 from a ternary surfactant system: surface roughening model
}

\author{
Bi-Chang Chen ${ }^{\text {a }}$, Man-Chien Chao ${ }^{\text {a }}$, Hong-Ping Lin ${ }^{\mathrm{b}}$, Chung-Yuan Mou ${ }^{\mathrm{a}, *}$ \\ a Department of Chemistry, National Taiwan University, 1 Roosevelt Rd sec 4, Taipei 106, Taiwan \\ ${ }^{\mathrm{b}}$ Department of Chemistry, National Cheng Kung University, Tainan 701, Taiwan
}

Received 30 October 2004; received in revised form 7 February 2005; accepted 9 February 2005

Available online 10 March 2005

\begin{abstract}
We have synthesized mesoporous silica SBA-16 at room temperature and low $\mathrm{pH}$ condition by using the surfactant system $\mathrm{C}_{8} \mathrm{TMAB} / \mathrm{SDS} / \mathrm{F} 127$ as template. Faceted single crystals of rhombdodecahedron form can be obtained under well-controlled conditions. Synthetic factors in controlling the morphology, including stirring, water content, the ionic surfactants and acidity are explored. A schematic theory for the formation of the equilibrium crystal structure based on surface roughening transition is proposed to explain the formation of faceted single crystal.
\end{abstract}

(C) 2005 Elsevier Inc. All rights reserved.

Keywords: Faceted crystal; Mesoporous; Molecular sieves; SBA-16; Surface roughening; F127

\section{Introduction}

Using micellar templating, mesoporous silica materials with periodic mesopores have been extensively synthesized in the last decade. One of the interesting developments is that mesoporous silica materials show a rich variety of morphology [1]. However, it is unusual for a periodic mesoporous material to show an well-defined single crystal morphology, in contrast to many microporous zeolites that have been synthesized with faceted shapes reflecting the crystal symmetries. Recently, mesoporous materials with well-faceted crystal morphology begin to emerge, corresponding to various space groups of cubic symmetry: Ia3d [2-5], Pm $3 n$ [6-12], and $\operatorname{Im} 3 m$ [13]. Faceted single crystals of mesoporous silica may be a good matrix materials for making microlasers for its well-defined internal optical gallery mode [12]. Fundamentally, studies on the crystal growth

\footnotetext{
* Corresponding author. Tel.: +886 233665251; fax: +886 223660954 .

E-mail address: cymou@ntu.edu.tw (C.-Y. Mou).
}

of mesoporous materials would be interesting by itself for it involves the less understood mesoscale as compared with simple atomic or ionic crystal.

In most of the reported cases of making symmetrically shaped single crystals of mesoporous materials the underlying principle is rarely explored [14]. The discoveries seem to be serendipity. There is definitely a lack of theoretical understandings of the crystallization of these single crystals. One is left to wonder the thermodynamic and kinetic controlling factors and the experimental conditions conducive to the formation of single crystals.

To begin with, the formation of well-faceted mesoporous organic-inorganic single crystal by itself is somewhat surprising. Most of the time, one would just have spherical or irregularly shaped particles. This is somewhat expected, if a liquid-like precursor state is involved where a lot of internal defects can be tolerated for the soft matter. In fact, most of our understandings about morphology of surfactant-templated mesoporous materials are based on the easily generated defect structures 
in lyotropic liquid crystal state [15]. Hence, faceted crystal would be rare. However, when one does make faceted mesoporous crystal, the exposed surfaces are the lowest energy surfaces and the yield can often be close to $100 \%$. Thermodynamics of the surface energy seems to be in control here instead of internal defects.

For understanding better the thermodynamics of the surface of surfactant/silicate organization, cubic structures such as MCM48, SBA-1 and SBA-16 are more desirable than the 2-D hexagonal system such as SBA-15. This is because in the later structure, the long and soft rod-micelle structure tends to be disrupted more easily by fluctuations and the morphology would be often dominated by internal defects. Recently, we reported the crystal facets of the cubic SBA-1 can be finely controlled by tuning the $\mathrm{pH}$ value near $\mathrm{pH}=2.0[9,10]$. The relative areas of the (110) and (100) planes of the 3D cubic $P m 3 n$ structure of SBA-1 can be adjusted by $\mathrm{pH}$ control [9] or the chain length of the surfactant $\mathrm{C}_{n} \mathrm{TMABr}[10]$. The success of making single crystals of SBA-1 reflects on the higher energy cost in generating internal defects for the spherical micelle based $P m 3 n$ structure.

One then would expect the well-packed micellar units in $\operatorname{Im} 3 m$ type structure a better candidate in making perfect crystals. In this paper, we would like to focus on the cubic mesoporous silica system SBA-16, templated by the amphiphillic copolymer F127, which has a bodycentered cubic arrangement of micelle/silicate spheres [16]. SBA-16 possesses a mesoporous structure with the cubic $\operatorname{Im} 3 m$ symmetry. Its best representation is by a triply periodic minimal surface, type I-WP or $\mathrm{C}(\mathrm{P})$. The effects of the synthesis parameters on the structural properties (not morphological) of the cubic $\operatorname{Im} 3 \mathrm{~m}$ SBA16 have been investigated systematically recently $[17,18]$. Recently, cubic mesoporous silica SBA-16 materials with a rhombdodecahedral or decaoctahedral shape have been synthesized by microwave reactions [19].

We would like to investigate how one can grow faceted mesoporous single crystals and to understand its underlying principles, using SBA-16 as an example. Here, we report the synthesis of mesoporous silica with faceted single crystal morphology using a ternary surfactant system $\left(\mathrm{C}_{8}\right.$ TMAB-SDS-F127) as a template under acidic condition. Recently, we used a similar ternary surfactant system ( $\left.\mathrm{C}_{16} \mathrm{TMAB}-\mathrm{SDS}-\mathrm{P} 123\right)$ as a template to obtain thin film of mesoporous materials SBA-15 with vertical channel [20]. The combination of the ionic surfactants system $\mathrm{C}_{n}$ TMAB-SDS provides one a mild perturbation to the structure but substantial change in morphology. Here we use the more hydrophilic F127 and $\mathrm{C}_{8}$ TMAB-SDS to obtain well-faceted single crystals of SBA-16. These single crystals possess exclusively uniform rhombdodecahedron shape $(\sim 5 \mu \mathrm{m})$ with almost $100 \%$ crystal yield and uniform pores $(\sim 4 \mathrm{~nm})$. It is the use of the ionic surfactants $\mathrm{C}_{8} \mathrm{TMAB}$ and SDS (sodium dodecyl sulfate) that give us extra control of the electric interaction between the micelle-units within the crystal. The other synthetic factors we explored, which affecting crystal morphology, are the dilution and stirring conditions. Summarizing these effects on the crystal shape, we then discuss the underlying thermodynamic controls of the formation of single crystals of mesoporous silica.

\section{Experimental}

In a typical synthesis of mesoporous silica single crystals, a ternary-surfactant mixture with the chemical components of $0.26 \mathrm{~g} \mathrm{C}_{8}$ TMAB: $0.3 \mathrm{~g}$ SDS: $0.7 \mathrm{~g}$ F127 $\left(\mathrm{EO}_{106} \mathrm{PO}_{70} \mathrm{EO}_{106}\right)$ were stirred in $50 \mathrm{~g} \mathrm{H}_{2} \mathrm{O}$ at $30^{\circ} \mathrm{C}$ to form a clear solution, where the molar ratio of $\mathrm{C}_{8} \mathrm{TMAB} / \mathrm{SDS}$ is 1.0 . The solution was directly poured into a $200 \mathrm{ml}$ dilute sodium silicate solution with $\left[\mathrm{SiO}_{2}\right]=70.0 \mathrm{mM}$, at $\mathrm{pH} \sim 3.0$. The reaction was continued under static condition at $30^{\circ} \mathrm{C}$. After several days of induction time, the solid products were collected by filtration, washed with water, and dried at $100{ }^{\circ} \mathrm{C}$. The resulting powders were calcined at $560^{\circ} \mathrm{C}$ for $6 \mathrm{~h}$ to remove the templates. For other mesoporous silica products, the synthetic process and chemical composition were the same except varying the $\mathrm{C}_{8} \mathrm{TMAB} / \mathrm{SDS}$ ratio.

The powder X-ray diffraction (XRD) patterns were recorded on non-oriented samples with a Scintag X1 diffractometer using $\mathrm{CuK} \alpha$ radiation. Thermogravimetric analysis (TGA) was carried out on a ULVAC TGA7000RH thermogravimetric system. The analysis was monitored and controlled by an on-line computer system. The heating rate was $10^{\circ} \mathrm{C} / \mathrm{min}$ and the carrier gas (air) flow rate was $60 \mathrm{ml} / \mathrm{min}$. $\mathrm{N}_{2}$ adsorption-desorption isotherms were obtained at $77 \mathrm{~K}$ on a Micrometrics ASAP 2010 analyzer. Before sorption measurements, the calcined samples were degassed at $200{ }^{\circ} \mathrm{C}$ for more than $6 \mathrm{~h}$ under $10^{-6}$ torr pressure. The TEM images were recorded on the Hitachi S- 800 with the acceleration voltage of $100 \mathrm{kV}$.

\section{Results}

X-ray powder diffraction (XRD) pattern of as-synthesized mesoporous silica crystals is shown in Fig. 1. The as-synthesized powders show three well-resolved XRD peaks in the region of $2 \theta=0.7-1.5^{\circ}$, which are indexed to the (110), (200), and (211) diffraction peaks of a body-centered cubic space group $(\operatorname{Im} 3 m)$.

Scanning electron microscope (SEM) images reveal that as-synthesized samples, synthesized without stirring, made with ternary surfactant mixture (at molar ratio $\mathrm{C}_{8} \mathrm{TMAB} / \mathrm{SDS}=1.0$ ) are composed of almost $100 \%$ single-crystal particles in morphology $(\sim 5 \mu \mathrm{m}$ in 


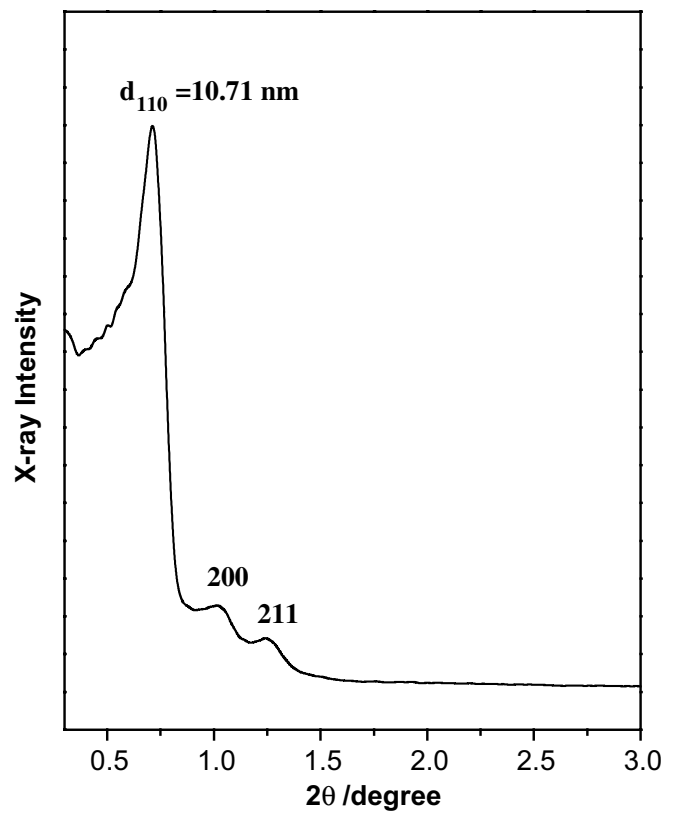

Fig. 1. XRD pattern of as-synthesized mesoporous single crystals.

size, Fig. 2A). Most of these particles have the shape of a rhombdodecahedron, consisting of 12 flat crystal faces (Fig. 3). These 12 faces can be indexed to the $\left\{\begin{array}{ll}1 & 0\end{array}\right.$ planes. The crystal has four 3 -fold axes and three 4-fold axes and exhibits cubic symmetry which belongs to $\operatorname{Im} 3 m$ point group class. Interestingly, the microcrystals in Fig. 2A appear to be non-sticking in contrast to the usual acid-synthesized mesoporous silica where the particles often stick together as aggregates. If the solution were stirred during synthesis, the SEM image of Fig. 2B show that much of the well-defined crystal faces disappear and irregular gyroid-like particles are formed instead.
Thermogravimetric analysis of the mesoporous single crystals (the sample of Fig. 2A) is shown in Fig. 4. A two-step profile is observed. The first step at about $180{ }^{\circ} \mathrm{C}$ is due to the weight loss of copolymer F127 $\left(\mathrm{EO}_{106} \mathrm{PO}_{70} \mathrm{EO}_{106}\right)$ and the weight loss at about $250{ }^{\circ} \mathrm{C}$ is indicative of the decomposition of the ionic surfactants $\mathrm{C}_{8} \mathrm{TMAB}$ and SDS.

An important synthetic factor in making the cubic mesoporous crystals is the molar ratio of $\mathrm{C}_{8} \mathrm{TMAB} /$ SDS employed. The SEM, XRD and physicochemical properties of mesoporous silica prepared with varying ratios are shown in Fig. 5, 6 and Table 1. In Fig. 5, distinct difference in morphology takes place when the $\mathrm{C}_{8} \mathrm{TMAB} / \mathrm{SDS}$ ratio is below 1.0. For $\mathrm{C}_{8} \mathrm{TMAB} /$ $\mathrm{SDS}=1 / 3$, multi-faceted (close to spherical shape) mesoporous silica are formed. Rhombdodecahedron was obtained at $\mathrm{C}_{8} \mathrm{TMAB} / \mathrm{SDS}$ ratio greater than 1.0. However, less well-defined rhombdodecahedron shapes were obtained at $\mathrm{C}_{8} \mathrm{TMAB} / \mathrm{SDS}=3 . \mathrm{A}_{8} \mathrm{TMAB}$-rich composition is necessary for the formation of cubic mesoporous single crystals.

The XRD patterns of selected samples at various $\mathrm{C}_{8} \mathrm{TMAB} / \mathrm{SDS}$ ratios are shown in Fig. 6A. For $\mathrm{C}_{8} \mathrm{TMAB} / \mathrm{SDS} \geqslant 1.0$, three well-resolved peaks can be indexed as (110), (200), (211) reflections corresponding to a cubic structure ( $\operatorname{Im} 3 m$ space group). However, in the case of $\mathrm{C}_{8} \mathrm{TMAB} / \mathrm{SDS}=1 / 3$, a broad peak with larger $d$ spacing is observed in the X-ray diffraction pattern. The mesostructure is less ordered. The nitrogen adsorption-desorption isotherms (Fig. 6B) of these materials are type IV with a type- $\mathrm{H}_{1}$ hysteresis loop. For $\mathrm{C}_{8} \mathrm{TMAB} / \mathrm{SDS} \geqslant 1.0$, the mesoporosities are similar. For $\mathrm{C}_{8} \mathrm{TMAB} / \mathrm{SDS}=1 / 3$, there are distinct differences in textural property compared to that with $\mathrm{C}_{8} \mathrm{TMAB} / \mathrm{SDS} \geqslant 1.0$. The physicochemical properties of mesoporous silica prepared using $\mathrm{C}_{8} \mathrm{TMAB} / \mathrm{SDS} /$ F127 are presented in Table 1. Compared to the
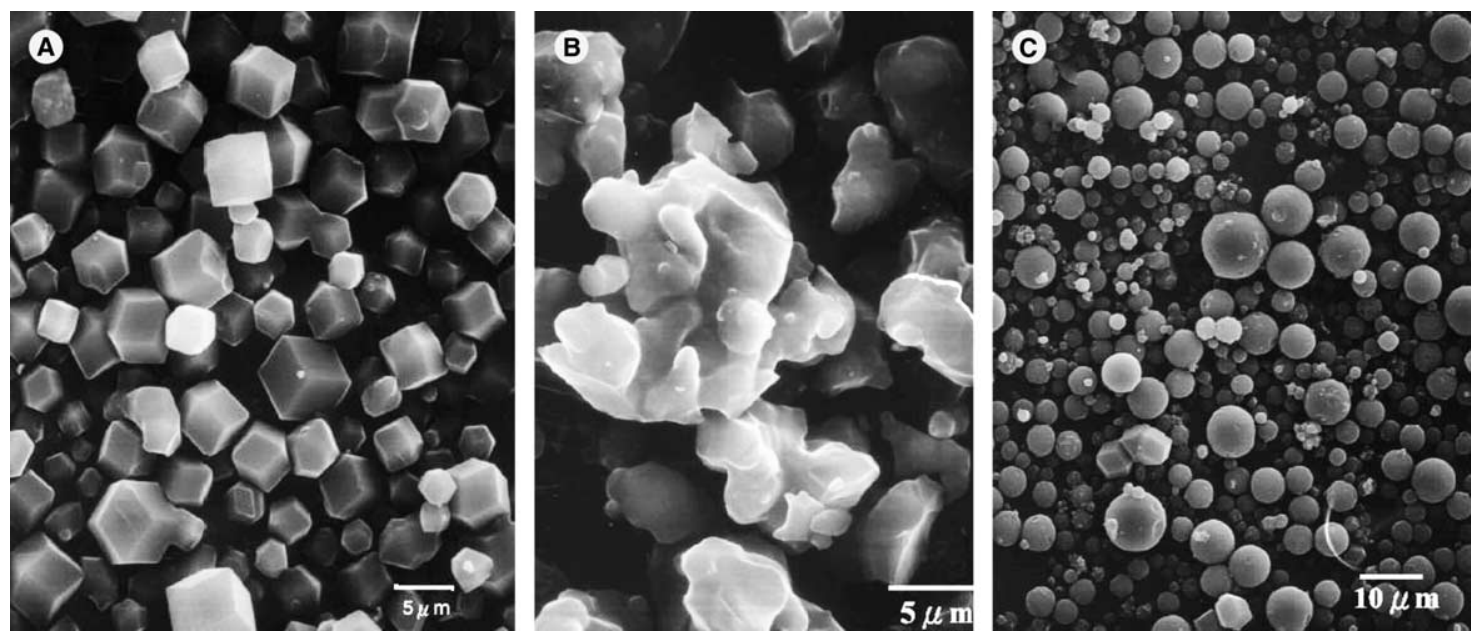

Fig. 2. The SEM image of mesoporous silica using $\mathrm{C}_{8} \mathrm{TMAB} / \mathrm{SDS} / \mathrm{F} 127 /$ sodium silicate system at molar ratio $\mathrm{C}_{8} \mathrm{TMAB} / \mathrm{SDS}=1.0$ : (A) $\mathrm{H}_{2} \mathrm{O}=200 \mathrm{ml}$; without stirring; (B) at $\mathrm{H}_{2} \mathrm{O}=200 \mathrm{ml}$; with stirring; (C) at $\mathrm{H}_{2} \mathrm{O}=100 \mathrm{ml}$; without stirring. 

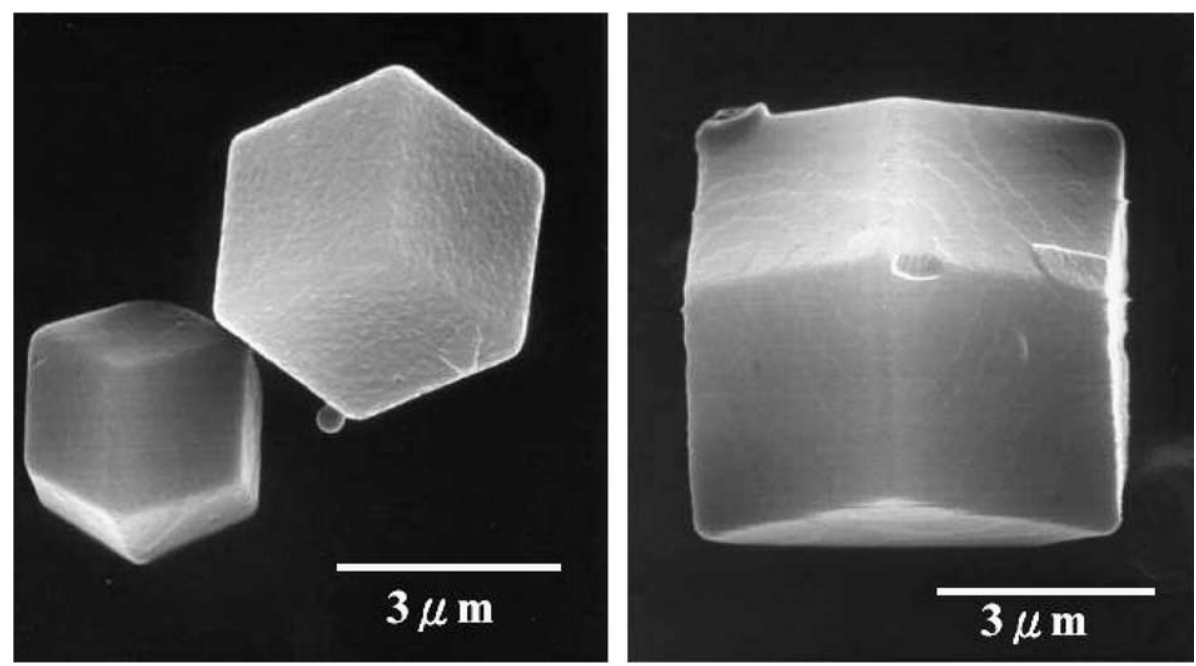

Fig. 3. SEM images along different axes of the SBA-16 mesoporous crystals.

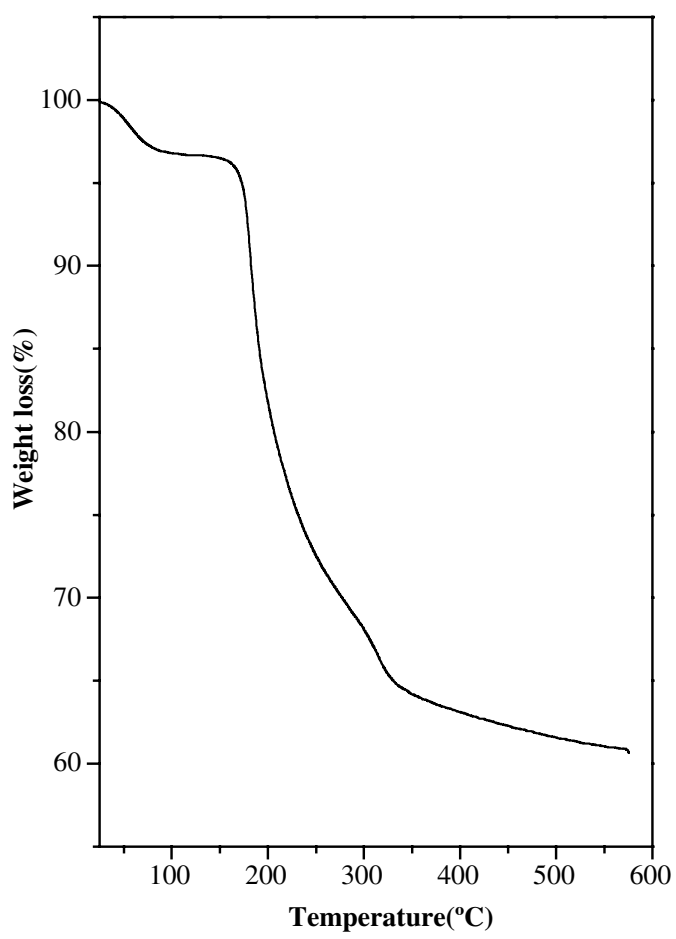

Fig. 4. The thermogravimetric analysis of mesoporous crystals using $\mathrm{C}_{8} \mathrm{TMAB} / \mathrm{SDS} / \mathrm{F} 127$ as directing agent, where $\mathrm{C}_{8} \mathrm{TMAB} / \mathrm{SDS}=1.0$.

mesoporosities of F127-templated silica (without the ionic surfactants), the pore size and pore volume of mesoporous crystals synthesized at $\mathrm{C}_{8} \mathrm{TMAB} / \mathrm{SDS}=1.0$ are smaller (pore size 5.2 vs. $3.5 \mathrm{~nm}$, pore volume 0.58 vs. $0.34 \mathrm{~cm}^{3} / \mathrm{g}$ ). On the contrary, in the case of $\mathrm{C}_{8} \mathrm{TMAB} /$ $\operatorname{SDS}=1 / 3$, the pore size and pore volume are similar to the pure F127-templated mesoporous silica. We also notice that the SBA-16 materials contain a large fraction of micropore volume which can reach as high as $50 \%$ of the total pore volume. This is due to the fact that the template molecule F127 $\left(\mathrm{EO}_{106} \mathrm{PO}_{70} \mathrm{EO}_{106}\right)$ possesses relatively big hydrophillic groups (EO) so that they penetrate substantially into the wall to give the corona micropore. However, we notice that the presence of the ionic surfactants $\mathrm{C}_{8} \mathrm{TMAB} / \mathrm{SDS}$ help to reduce the surface area and pore volume when compared with mesoporous materials synthesized with F127 only.

The second factor in the synthesis of cubic mesoporous crystals is the amount of water used. For normal synthesis of cubic silica crystals (the amount of water used at $200 \mathrm{ml}$ ), one obtained faceted rhombdodecahedron crystals as shown in Fig. 2A. If the amount of water is reduced to half of that in the synthesis of crystals, spherical-like particles (Fig. 2C) of the mesoporous materials is obtained. Higher concentration of silicate solution results in non-uniform spherical particles with high yield. For the samples prepared at lower water content, it takes less time to form the spherical morphology due to the faster condensation rate. Although the formation of spherical particles is rather rapid, the mesostructure remains in $\operatorname{Im} 3 m$ symmetry, which is the same as that of the cubic crystals (see XRD patterns in Fig. 7A). Moreover, the XRD pattern of the spherical particles contains peaks at somewhat higher scattering angles, $d(110)=9.85 \mathrm{~nm}$ than that of cubic crystals with $d(110)=10.71 \mathrm{~nm}$. The nitrogen adsorption-desorption isotherms are shown in Fig. 7B. They are characteristics of type IV with a $\mathrm{H}_{1}$ hysteresis loop. With the decrease of water content, there is a small but significant shrinkage in pore size and micropore volume. The physicochemical properties of the two samples are presented in Table 2.

\section{Discussions}

There are many synthetic factors that affect the crystal morphology of the SBA-16. We would like to discuss 


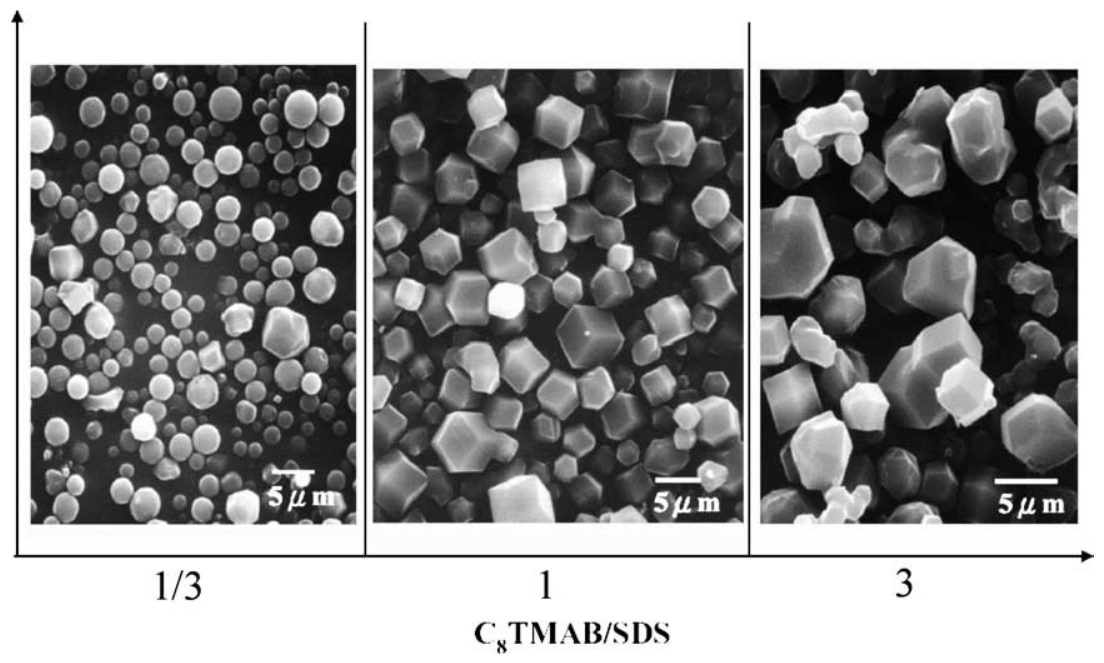

Fig. 5. SEM images of the SBA-16 mesoporous crystals at different ratios of $\mathrm{C}_{8} \mathrm{TMAB} / \mathrm{SDS}$.
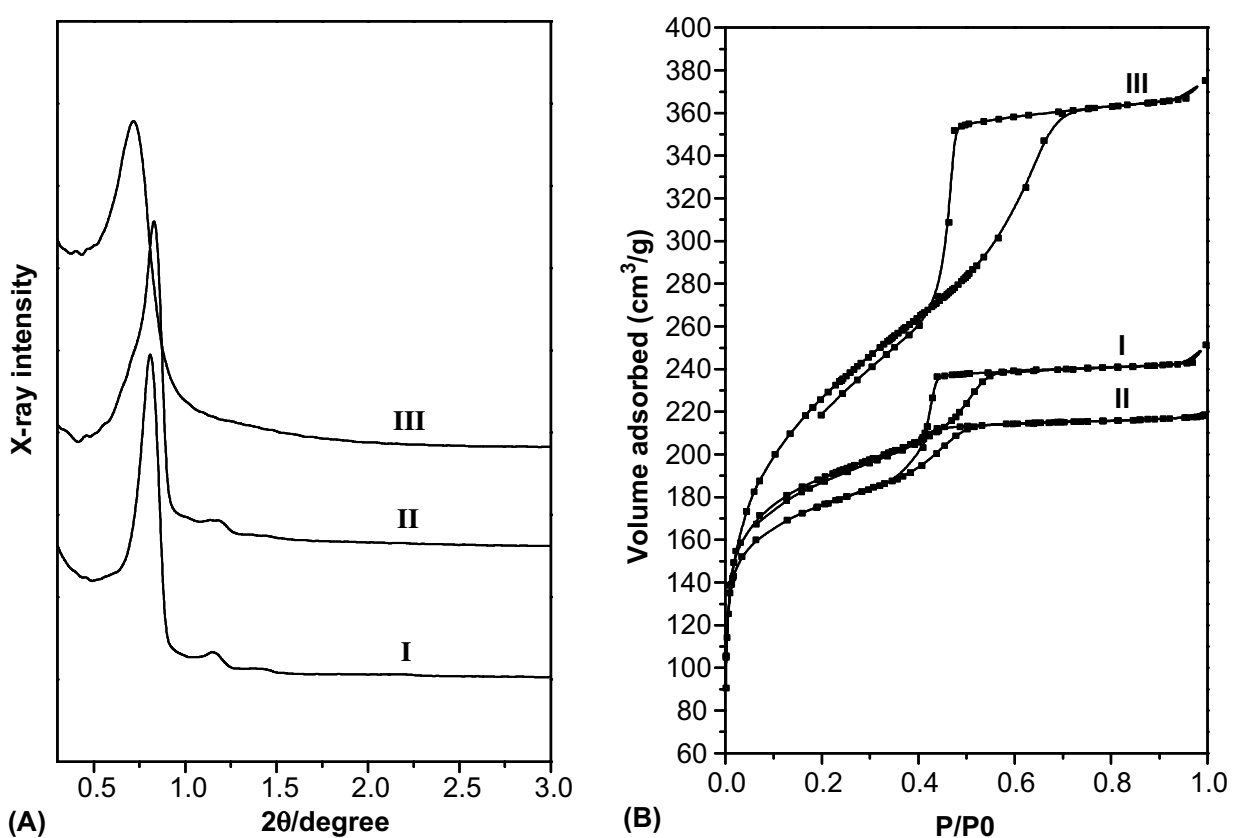

Fig. 6. The XRD patterns (A) and nitrogen adsorption isotherm plots (B) of calcined mesoporous silica using $\mathrm{C}_{8} \mathrm{TMAB} / \mathrm{SDS} / \mathrm{F} 127$ as template at various $\mathrm{C}_{8} \mathrm{TMAB} / \mathrm{SDS}$-ratio: (I) $\mathrm{C}_{8} \mathrm{TMAB} / \mathrm{SDS}=3$; (II) $\mathrm{C}_{8} \mathrm{TMAB} / \mathrm{SDS}=1$; (III) $\mathrm{C}_{8} \mathrm{TMAB} / \mathrm{SDS}=1 / 3$.

Table 1

Textural properties of mesoporous silica with $\mathrm{C}_{8} \mathrm{TMAB} / \mathrm{SDS} / \mathrm{F} 127$ as template

\begin{tabular}{|c|c|c|c|c|c|}
\hline $\mathrm{C}_{8} \mathrm{TMAB} / \mathrm{SDS}$ & $d_{110}(\mathrm{~nm})$ & $S_{\text {BET }}\left(\mathrm{cm}^{2} / \mathrm{g}\right)$ & $D_{\text {pore }}(\mathrm{nm})$ & $V_{\text {micro }}\left(\mathrm{cm}^{3} / \mathrm{g}\right)$ & $V_{\mathrm{t}}\left(\mathrm{cm}^{3} / \mathrm{g}\right)$ \\
\hline 3 & 10.85 & 622 & 4.0 & 0.20 & 0.37 \\
\hline 1 & 10.71 & 588 & 3.5 & 0.17 & 0.34 \\
\hline $1 / 3$ & 11.09 & 796 & 5.5 & 0.17 & 0.57 \\
\hline $\mathrm{F} 127^{\mathrm{a}}$ & - & 927 & 5.2 & 0.30 & 0.58 \\
\hline
\end{tabular}

${ }^{a}$ Without ionic surfactants.

them and their theoretical implications. There are two processes involved in the organization of the mesostructure: the surfactant/silicate self-assembly and the silica condensation. One needs a well-separated time scale of the above two processes in order to have good morphological control. If the silica condensation rate were too 

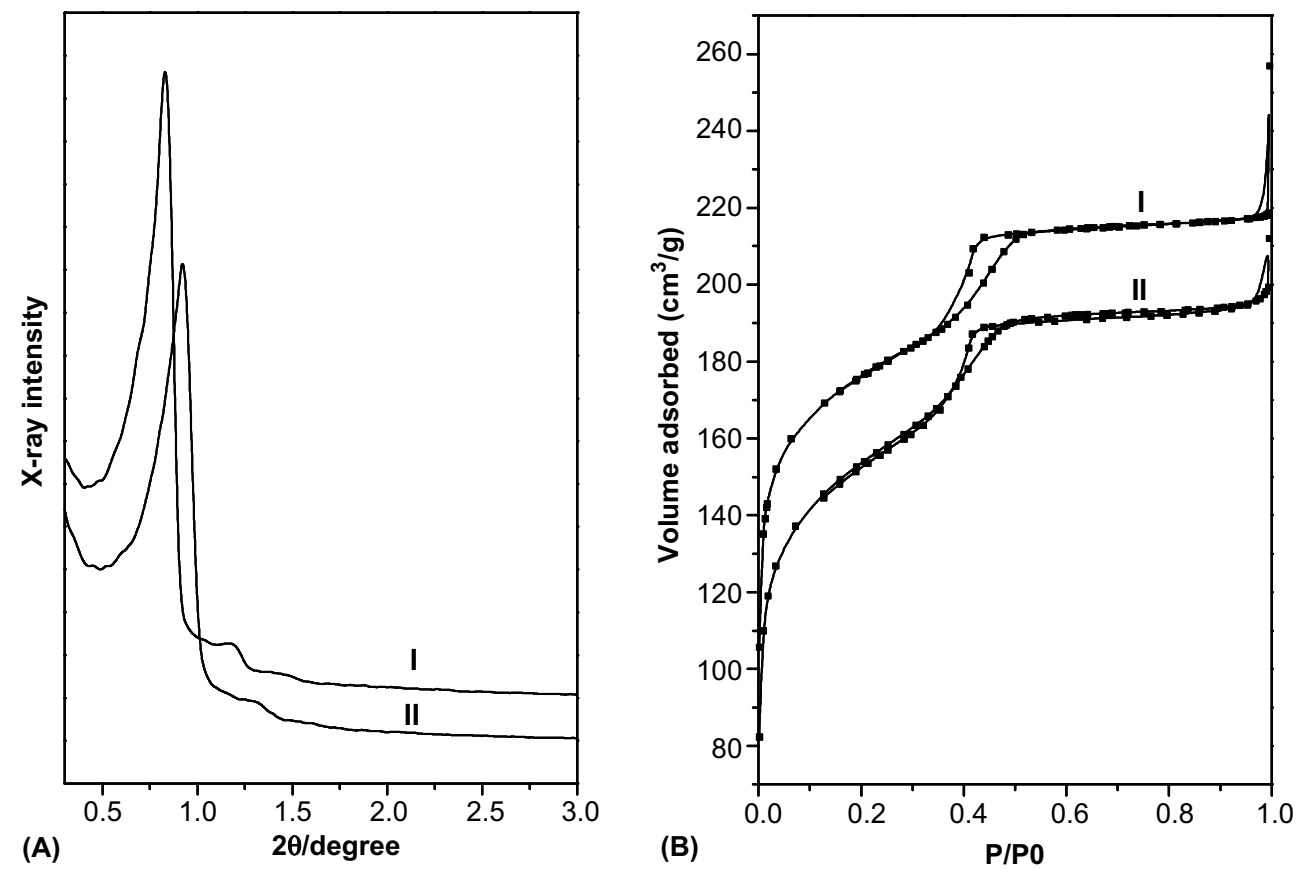

Fig. 7. The XRD patterns (A) and nitrogen adsorption-desorption isotherms; (B) of calcined samples synthesized with different amount of $\mathrm{H}_{2} \mathrm{O}$ : (I) calcined cubic crystals and (II) calcined spherical particles.

Table 2

Physicochemical properties of mesoporous silica synthesized with different amount of $\mathrm{H}_{2} \mathrm{O}$ (I) cubic crystals (200 ml) and (II) spherical particles $(100 \mathrm{ml})$

\begin{tabular}{llllll}
\hline & $d_{110}(\mathrm{~nm})$ & $S_{\text {BET }}\left(\mathrm{cm}^{2} / \mathrm{g}\right)$ & $D_{\text {pore }}(\mathrm{nm})$ & $V_{\text {micro }}\left(\mathrm{cm}^{3} / \mathrm{g}\right)$ & $V_{\mathrm{t}}\left(\mathrm{cm}^{3} / \mathrm{g}\right)$ \\
\hline Cubic particles (I) & 10.71 & 588 & 3.5 & 0.17 & 0.34 \\
Spherical particles (II) & 9.85 & 516 & 3.0 & 0.10 & 0.32 \\
\hline
\end{tabular}

fast, one would be trapped in non-equilibrium structure (of irregular shape) before the structural relaxation of the liquid crystalline phase is complete. To have a good equilibrium structure, one needs to slow down the silica condensation process. Synthetic factors to slow down silica condensation are $\mathrm{pH}$ control, stirring and dilution.

\section{1. $p H$ control}

In a typical synthesis of mesoporous silica single crystal, the quaternary system $\mathrm{C}_{8} \mathrm{TMAB} / \mathrm{SDS} / \mathrm{F} 127 /$ silicate is under static condition for several days at $30^{\circ} \mathrm{C}$ and $\mathrm{pH}=3.0$. It is near the isoelectric point (at $\mathrm{pH}=2.0$ ) of silica where silica condensation is the slowest [1]. Together with the low temperature condition, the $\mathrm{pH}$-sensitive silica condensation rate is rather slow. Sometimes, the induction period for crystallization is as long as a week. In our previous report of single crystal of SBA1 , the optimum condition for forming cubic crystal is at $\mathrm{pH}=2$ with very long induction time [9]. We note here in passing that we used sodium silicate as the silicon source in making SBA-16 instead of the usual TMOS or TEOS [16]. This is to make the condensation reaction to be more sensitive to $\mathrm{pH}$ value around 2. This low $\mathrm{pH}$ condition (1.0-3.0) is often applied for making mesoporous single crystals $[10,13]$.

\subsection{Stirring vs. static condition}

Static condition for the formation of cubic silica crystals is needed. This is also a necessary condition for diffusion-limited reaction to slow down the growth of the crystal. If the solution were stirred, the supply of ingredients from solution would be much accelerated and the growing crystal would not have enough time to anneal the defects. The morphology would then be defect-dominated. Fig. 2B is the SEM image of the formation of mesoporous cubic crystals with stirring; most of the well-defined crystal faces disappear and gyroid-like particles form. The curved surface of gyroid is a signature of the underlying topological defects [15]. Also we notice there is an extensive aggregation. The product appears to consist of many particles sticking together. Nonetheless, we note that in Fig. 2B some faceted surfaces still preserve under stirring. In fact, the milder the stirring the more cubic crystal one would get. In the literature where micron-sized single crystals are made, static conditions are mostly employed to obtain high yield of well-faceted crystals. 


\subsection{Water content}

In our synthesis, we used a large amount of water relative to the ingredients of SBA-16. The dilute synthetic condition would also slow down the self-assembling rate of surfactant and silica species to provide a time long enough for the assembly of micron-sized single crystals. The induction periods are pretty long, often in days. Previously, Pang and coworkers [21] reported hexagonally faceted MCM-41 morphology using extremely dilute surfactant concentration. When using a surfactant concentration at $0.020 \mathrm{M}$, we also found the $\mathrm{C}_{n}$ TMAX-templated SBA-1 mesoporous silica turns to single crystal form [9].

From the low-magnification SEM observations, the yield of the microcrystal is higher than $98 \%$. We practically do not see other shapes. The low concentration and the mild temperature employed also decrease the contact frequency between the microcrystals such that they do not stick together. In Ref. [19], SBA-16 crystals were made by microwave heating. The yield of faceted SBA-16 crystal was not high and they tend to stick together extensively, perhaps due to the higher concentration and the microwave heating condition employed. In many applications, one would like to have non-sticking microcrystals.

\subsection{Theoretical consideration}

Before discussing the faceting of the crystal, we need first give some theoretical background about faceted crystal growth of crystals near equilibrium. If a crystal has a microscopically smooth face, the face appears as a macroscopic facet. Roughening of the surface on a microscopic scale results in shrinkage and disappearance of the corresponding facet. The process, disappearance of facets due to roughening of the face, is called the roughening transition.

For lyotropic crystal, in the early stage of growth, one would have a soft matter of self-assembly of micelles (including the silicate counterions) and their packing into lyotropic mesophases. The morphology is determined at this stage. Later silica condensation further fixes the crystal shape. Compared to simple atomic or ionic crystals, the main differences would be the much larger spacing $d$ of the crystallographic planes. The large value of the lattice constant is responsible for the large number of facets. There is a surface roughening temperature $T_{\mathrm{R}}$ corresponding to each surface of certain Miller index, below which the surface is flat. According to theory of surface roughening [22], the surface roughening temperature $T_{\mathrm{R}}$ is proportional to $d^{2}$ as given by the universal relation Eq. (1) where $d$ is the periodicity of the lattice along the normal to the interface, in practice the step height in roughening. As for $\gamma$, it is the value of the surface tension of the interface considered.
$k_{\mathrm{B}} T_{\mathrm{R}}=2 \gamma d^{2} / \pi$

For the lyotropic liquid crystal [23], the interfacial tension $\gamma$ tends to be much smaller compared to liquid/air surface tension. However, the 10-100 fold larger value of the $d$-spacings compared to atomic solid leads to a roughening transition temperature higher than room temperature (for example in the $\mathrm{C}_{12} \mathrm{EO}_{6} /$ water system [23]). Thus for lyotropic mesophases, room temperature $(293 \mathrm{~K})$ is very cold compared to the energy scale involved in the roughening of the facets even for high Miller index surfaces. The consequence is that in mesoporous silica materials one would often observe an extremely large number of facets to the extent of approaching spherical morphology. Indeed the spherical form is the predominant morphology for most of the cubic phase materials.

Now the reason for the formation of the $\{110\}$ faceted crystal of our SBA-16 can be understood from Eq. (1). The surfaces with $d$-spacing next smaller than $\{110\}$ surfaces are the $\{200\}$ surfaces. If the values of $\gamma$ are the same for both surfaces, which is not true in general, then we have $T_{\mathrm{R}}(110) / T_{\mathrm{R}}(200)=2\left(d_{110} / d_{200}=\right.$ $\sqrt{2})$. The roughening temperature of the $\{110\}$ surface is at least twice higher than the $\{200\}$ surface. If $T_{\mathrm{R}}(110)$ were less than $2 T, T$ being the reaction temperature, then $\{110\}$ surfaces would persist while the $\{200\}$ surfaces and all the higher order surfaces would disappear.

\subsection{The role of ionic surfactants}

In this work, the crucial ingredients, in addition to the main surfactant F127, are the ionic surfactants $\mathrm{C}_{8} \mathrm{TMAB}$ and SDS. From TGA analysis, the F127 copolymer is the major organic component in as-synthesized materials $(\sim 25 \%$ by weight) and the uptake of ionic surfactant is relatively minor $(\sim 6 \%)$. Because of the strong specific interaction between $\mathrm{C}_{n} \mathrm{TMAB}$ and SDS, they are up-taken together as pseudo-zwitterionic form and interact less strongly with silicates [20]. On the other hand, the neutral F127 (or P123 in [20]) interacts strongly with the condensing sodium silicate to form the SBA-16 structure. The incorporation of the ionic surfactants in the micellar building block in the SBA-16 structure leads to a better structure order. This helps the formation of single crystal. Previously, Zhao et al. [13] used F108 and highly charged salts such as $\mathrm{K}_{2} \mathrm{SO}_{4}$ to make faceted single crystals of $\operatorname{Im} 3 m$ symmetry. The strong screening of ionic interaction probably helps selecting the $\{110\}$ surface. Our use of the ionic surfactant pair may have the same function. This probably leads to a decrease of $\gamma$ in Eq. (1) such that $T_{\mathrm{R}}(110)$ is brought closer but still above room temperature. Due to the lower interaction among the particles on the $\{200\}$ surface and also the smaller $d_{200}$ spacing, the 
roughening transition temperature for the $\{200\}$ surfaces are then brought below room temperature. Thus we would have selected a faceted cubic crystal with $\left\{\begin{array}{lll}1 & 1 & 0\end{array}\right.$ external surfaces only.

In synthesis, the $d$-spacings of SBA-16 can be varied to some extent. Then, according to Eq. (1), the morphology can be adjusted. In our case, when less water (at $100 \mathrm{ml}$ ) was used, we obtained a spherical morphology (Fig. 2C). We then examine the d-spacings (from Fig. 7) of the samples corresponding to Fig. $2 \mathrm{~A}$ and C. The $d^{2}$ factor in Eq. (1) is smaller by 0.845 times (Table 2). $T_{\mathrm{R}}$ for all surfaces are then below the reaction temperature and the morphology becomes spherical.

In summary, the intriguing idea of roughening transition temperature seems to explain well the crystal shape of mesoporous silica. However, further systematic works are necessary to understand this novel phenomenon.

\subsection{Why does the single crystals are always in micron} size?

From all the literature reports on the faceted single crystals of mesoporous silica [2-13], one may conclude the crystal sizes are always in the scale of microns. Larger crystals have never been made. From the above discussions, two reasons for not forming mesoporous single crystal of bigger size may be proposed. First, the bigger the particle the more topological defects would be formed and the longer time it takes to anneal the defects out. Even at the most favorable $\mathrm{pH}$ and temperature condition, silica condensation is always a non-negligible process constantly going on. So we do not really have the option to wait extremely long time to obtain a large crystal. The bigger particles would be then more easily trapped irregularly shaped.

The second possible scenario is to suppose forming first big spherical particle beyond micron size. In a hypothetical mechanism, then the spheres may transform themselves into faceted cubes by surface nucleation. There have been reports of mesoporous sphere of macroscopic size [24]. However, when the curvature of the sphere is very small, the growing surface would be close to flat. Then there is very little thermodynamic advantage to convert such surface to a completely flat surface of low Miller index. The free energy barrier for the nucleation of a flat surface (from of a slightly curved surface) would be then very high because of the edge effect would always be against such conversion.

\section{Conclusions}

We have successfully synthesized SBA-16 mesoporous silica at room temperature and low $\mathrm{pH}$ condition by using the ternary surfactant system $\mathrm{C}_{8} \mathrm{TMAB} / \mathrm{SDS} /$
F127 as template. Faceted single crystals of cubic form were obtained under well-controlled synthetic conditions. Synthetic factors in controlling the crystal morphology include stirring, water content, the ionic surfactants and acidity. We have found changing these conditions for a slower reaction rate always favors the formation of faceted single crystals.

The crystal surfaces are dominated by the lowest energy surfaces $\{110\}$ of the $\operatorname{Im} 3 m$ structure of SBA- 16 . Their formation indicates equilibrium crystal surfaces. We propose to explain the formation of the faceted crystal structure based on a theory of surface roughening transition, which had been developed for theory of crystal shape for normal atomic crystals (such as $\mathrm{Pb}$ ). The domination by a few crystal surfaces may be explained by the rapid decreasing trend of roughening temperature such that the surfaces with higher Miller indexes disappear. In light of this theory, more synthetic factors may be explored. Their influence on the morphology can be viewed in light of Eq. (1).

Our theory is based on equilibrium thermodynamics only. We do not investigate the problem of the growth kinetics of the crystal. The dynamical evolution is another problem worth investigating in the future.

There seems to be an upper-limit of the size $(\sim \mu \mathrm{m})$ of single crystals of mesoporous silica. We explain this observation based on two considerations: the proliferation of structure defects and the energy barrier of making a facet surface when the particle becomes too big. However, one cannot exclude the possibility of making faceted mesoporous silica crystal of macroscopic size if nucleation can be suppressed so much that growth mode would persist.

We are still far from understanding the formation of single crystals of mesostructured periodical organicinorganic hybrids. A thorough understanding of the underlining physicochemical process may help us toward the fabrication of high quality mesoporous silica single crystals. They may have good optical applications. It may incorporate guest molecules such as dye in optical applications for the strong gallery reflection mode inside the crystal.

\section{Acknowledgment}

This work was supported by a grant from the Ministry of Education of Taiwan through Academy Excellent program.

\section{References}

[1] H.P. Lin, C.Y. Mou, Acc. Chem. Res. 35 (2002) 927.

[2] J.M. Kim, S.K. Kim, R. Ryoo, Chem. Commun. 2 (1998) 259. 
[3] P.N. Trikalitis, K.K. Rangan, B. Bakas, M.G. Kanatzidis, J. Am. Chem. Soc. 124 (2002) 12255.

[4] Y.D. Xia, R. Mokaya, J. Mater. Chem. 13 (2003) 657.

[5] M. Kaneda, T. Tsubakiyama, A. Carlsson, Y. Sakamoto, T. Ohsuna, O. Terasaki, S.H. Joo, R. Ryoo, J. Phys. Chem. B 106 (2002) 1256.

[6] (a) S. Che, Y. Sakamoto, O. Terasaki, T. Tatsumi, Chem. Mater. 13 (2001) 2237;

(b) S. Che, S. Lim, M. Kaneda, H. Yoshitake, O. Terasaki, T. Tatsumi, J. Am. Chem. Soc. 124 (2002) 13962.

[7] S. Guan, S. Inagaki, T. Ohsuna, O. Terasaki, J. Am. Chem. Soc. $122(2000) 5660$.

[8] A. Sayari, S. Hamoudi, Y. Yang, I.L. Moudrakovski, J.R. Ripmeester, Chem. Mater. 12 (2000) 3857.

[9] M.C. Chao, D.S. Wang, H.P. Lin, C.Y. Mou, J. Mater. Chem. 13 (2003) 2853.

[10] M.C. Chao, H.P. Lin, C.Y. Mou, Chem. Lett. 33 (2004) 672.

[11] Z.D. Zhang, B.Z. Tian, S.D. Shen, J. Fan, B. Tu, Q.Y. Kong, F.S. Xiao, S.L. Qiu, D.Y. Zhao, Chem. Lett. 6 (2002) 584.

[12] M.P. Kapoor, S. Inagaki, Chem. Mater. 14 (2002) 3509.

[13] C.Z. Yu, B.Z. Tian, J. Fan, G.D. Stucky, D.Y. Zhao, J. Am. Chem. Soc. 124 (2002) 4556.
[14] C.Z. Yu, J. Fan, B.Z. Tian, D.Y. Zhao, Chem. Mater. 16 (2004) 889.

[15] H. Yang, G.A. Ozin, C.T. Kresge, Adv. Mater. 10 (1998) 883.

[16] (a) D. Zhao, J. Feng, Q. Huo, N. Melosh, G.H. Fredrickson, B.F. Chmelka, G.D. Stucky, Science 279 (1998) 548; (b) D. Zhao, Q. Huo, J. Feng, B.F. Chmelka, G.D. Stucky, J. Am. Chem. Soc. 120 (1998) 6024.

[17] P. Van Der Voort, M. Benjelloun, E.F. Vansant, J. Phys. Chem. B 106 (2002) 9027.

[18] C.F. Cheng, Y.C. Lin, H.H. Cheng, S.M. Liu, H.S. Sheuy, Chem. Lett. 33 (2004) 262.

[19] Y.K. Hwang, J.S. Chang, Y.U. Kwon, S.E. Park, Micropor. Mesopor. Mater. 68 (2004) 21.

[20] B.C. Chen, H.P. Lin, M.C. Chao, C.Y. Mou, C.Y. Tang, Adv. Mater. 16 (2004) 1657.

[21] Q. Cai, W.Y. Lin, F.S. Xiao, W.Q. Pang, X.H. Chen, B.S. Zou, Micropor. Mesopor. Mater. 32 (1999) 1.

[22] H.P. Bonzel, Phys. Rep. 385 (2003) 1.

[23] P. Pieranski, P. Sotta, D. Rohe, M. Imperor-Clerc, Phys. Rev. Lett. 84 (2000) 2409

[24] C.P. Kao, H.P. Lin, C.Y. Mou, J. Phys. Chem. Solid 62 (2001) 1555. 